\title{
STRUCTURAL BEHAVIOR OF AQUEOUS SOLUTIONS USING TIME DOMAIN REFLECTOMETRY TECHNIQUE
}

\author{
A.C. KUMBHARKHANE
}

PACS 71.20.Nr; 72.20.Pa

School of Physical Sciences, Swami Ramanand Teerth Marathwada University

(Nanded - 431 606, Maharashtra, India; e-mail: akumbharkhane@ yahoo. co. in)

\begin{abstract}
We have developed and established the TDR technique that provides information about the dielectric permittivity in the frequency range from $10 \mathrm{MHz}$ to $30 \mathrm{GHz}$. The dielectric permittivity for the aqueous solutions can be explained by using a hydrogen-bond model by assuming the formation of hydrogen bonds between waterwater and water-solute pairs. The orientational correlation between neighbouring molecules due to hydrogen bonds is determined in terms of the Kirkwood correlation factor. The number of hydrogen bonds in some aqueous solutions is computed.
\end{abstract}

\section{Introduction}

Importance of measuring the dielectric constant of a liquid lies in the fact that it provides valuable information about the ordering of the molecules in the liquid state. Water is a hydrogen bonded liquid. Hydrogen bonding is a complex phenomenon in the liquid state due to the uncertainty in identifying the particular bonds and the number of molecules involved. The local structures of hydrogen bonded liquids are complicated due to molecular clusters and network structures through hydrogen bonds. The importance of hydrogen bonding as a force governing the structure and the dynamics of chemical and biological systems has been pointed out in a lot of papers [1-7]. A water molecule has permanent dipole moment $=1.85 \mathrm{D}$ and possesses a polarizability which is an additional dipole induced by an electric field and is proportional to its magnitude. The dipole moment of water undergoes a considerable rotation about one of its hydrogen bonds by breaking its other bond. The water structure is easily changed, if an organic compound having an acceptor or donor for the hydrogen bond is added. The molecular network formed by the hydrogen bonding of a non-hydrogen molecule with neighboring molecules exhibits many important properties due to its three-dimensional tetrahedral structure. The structure of water is one of the interesting subjects in the variety of scientific fields in chemistry, physics, biology, electronics engineering, and civil engineering [8-10].
Many dielectric studies have been reported on aqueous solutions in order to investigate the hydrogen bond structures in mixtures. Dielectric relaxation measurements present information on the water structure in aqueous solutions [11-14]. Microwave dielectric relaxation spectroscopy is a powerful tool for measuring the broadband dielectric behavior at microwave frequencies [15-21]. Time Domain reflectometry (TDR) $[1,7,17]$ has been proven to be a very effective and accurate method for the determination of a dielectric constant and losses in the wide frequency range in the single measurement. In this work, we performed TDR measurements with flat-end sample cells for aqueous systems of acetone, alcohols, and dioxane in the frequency range $10 \mathrm{MHz}$ to 30 GHz. The static dielectric constant and the Kirkwood correlation factors for aqueous solutions have been determined using the hydrogen bonded model as suggested by Luzar [22]

\section{Experimental Method}

The dielectric spectra were obtained by the time domain reflectometry (TDR) technique [1,6,7]. A Tektronix digital analyzer DSA8200 with the sampling module 80E08 has been used, and this module provides the accurate oscilloscopic measurement with a selectable bandwidth of $20 \mathrm{GHz}$ or $30 \mathrm{GHz}$. Figure 1 shows the experimental setup based on the time domain reflectometry technique. A repetitive fast rising $250 \mathrm{mv}$ voltage pulse of $200 \mathrm{KHz}$ with 18 ps incident rise time was fed through a coaxial line system with the impedance of $50 \mathrm{Ohm}$. The coaxial semirigid copper cable EZ86M17 (Huber, Suhner Electronics Pvt. Ltd.) with flat end was used. The dimensions of the used cable are: inner diameter of the outer conductor $-2.2 \mathrm{~mm}$, outer diameter of the central conductor $-0.51 \mathrm{~mm}$, and the diameter of a dielectric $-1.68 \mathrm{~mm}$, respectively. A sampling oscilloscope monitors changes in pulse after the reflection from the line end. Reflected pulse amplitudes without sample, $R_{1}(t)$, and with sample, $R_{x}(t)$, were recorded in a time window of 2 ns and digitized in the 2000 record length. The 
Digital Signal Analyzer DSA 8200

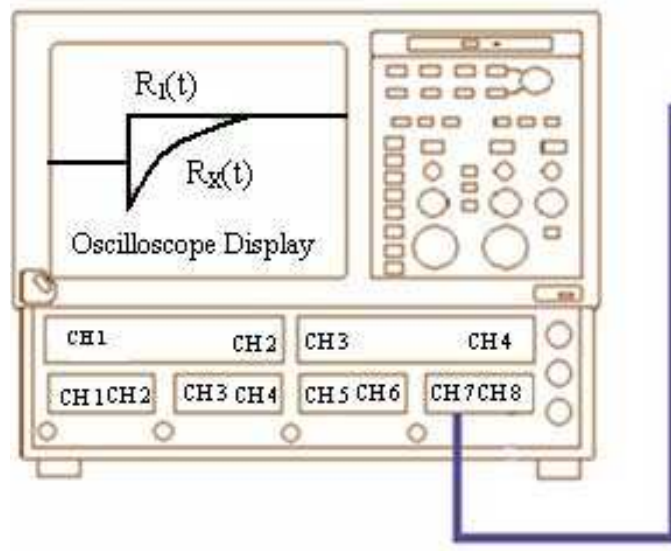

Fig. 1. Block Digram of TDR
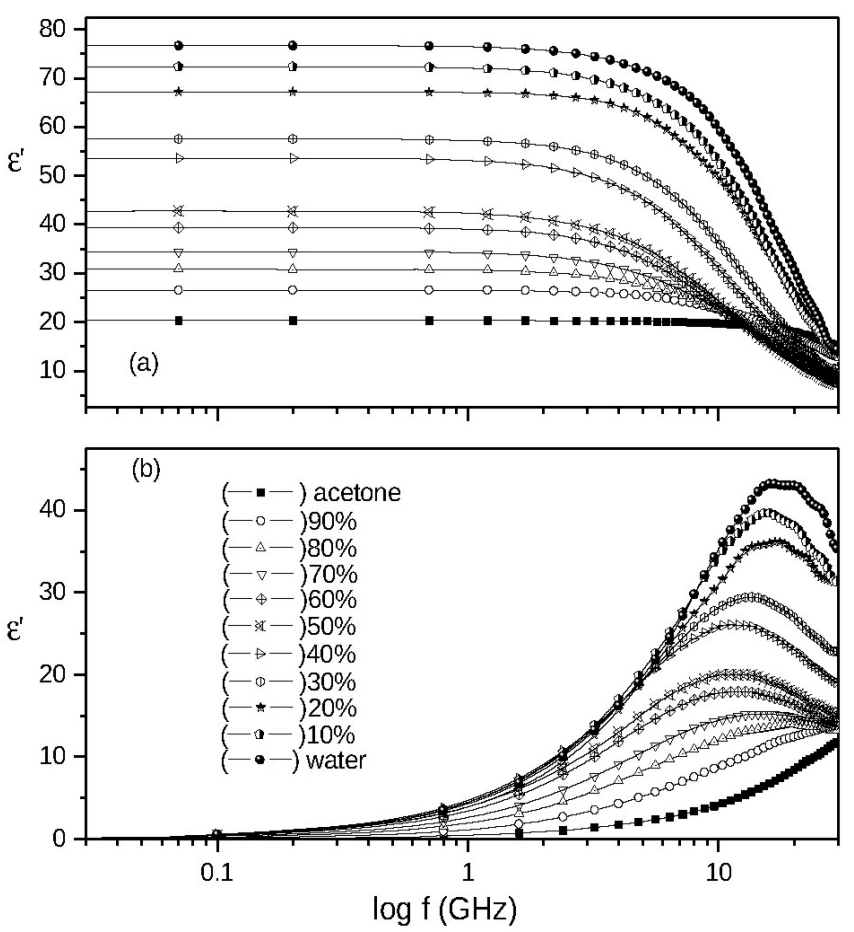

Fig. 2. Complex permittivity $\left(\varepsilon^{\prime}\right.$ and $\left.\varepsilon^{\prime \prime}\right)$ vs the frequency for different volume $\%$ of acetone in water at $25{ }^{\circ} \mathrm{C}$

Fourier transformations of the pulses and the data analysis were done to determine the complex permittivity spectra in the frequency range $10 \mathrm{MHz}$ to $30 \mathrm{GHz}[6,7]$. Figure 2 gives an example of frequency-dependent com- plex permittivity spectra (real $\left(\varepsilon^{\prime}\right)$ and imaginary $\left.\left(\varepsilon^{\prime \prime}\right)\right)$ for acetone-water mixtures at $25{ }^{\circ} \mathrm{C}$.

\section{Results and Discussion}

We have performed a non-linear least squares fit procedure for the dielectric spectrum of the aqueous solution, in order to determine the dielectric relaxation parameters. Generally, the dielectric spectrum for water can be described using the Debye equation. Therefore, the complex permittivity spectrum of aqueous solutions was fitted to the Harviliak-Negami equation [18].

$\varepsilon^{\infty}(\omega)=\varepsilon_{\infty}+\frac{\left(\varepsilon_{0}-\varepsilon_{\infty}\right)}{\left[1+(j \omega \tau)^{(1-\alpha)]^{\beta}}\right.}$,

where $\varepsilon_{0}$ is the static permittivity, $\varepsilon_{\infty}$ is the permittivity at high frequency, $\tau$ is the relaxation time, $\alpha$ and $\beta$ are the empirical parameters for the distribution of relaxation times with values between 0 and 1 . The HavriliakNegami equation includes three relaxation models. The Debye model $(\alpha=0$ and $\beta=1)$ suggests a single relaxation time, while the Cole-Cole $(0 \leq \alpha \leq 0$ and $\beta)$ and Cole-Davidson $(\alpha=0$ and $0 \leq \beta \leq 1)$ models both suggest a distribution of relaxation times. The values of $\alpha$ and $\beta$ indicate the width of the distribution. The significance of hydrogen bonds for the dielectric properties of the mixture can be studied using the Luzar model [22]. The model is successfully applied to a waterdimethylsulfoxide system [15]. It is based on the statistical behavior of solute-solvent interaction, by assuming that only solute-solute and solute-solvent pairs are 


\begin{tabular}{|c|c|c|c|c|c|c|c|}
\hline Molecular Parameter & $25^{\circ} \mathrm{C}$ & $25^{\circ} \mathrm{C}$ & $15^{\circ} \mathrm{C}$ & $10^{\circ} \mathrm{C}$ & $5^{\circ} \mathrm{C}$ & $0{ }^{\circ} \mathrm{C}$ & $-6^{\circ} \mathrm{C}$ \\
\hline Dipole moment of water $\left(\mu_{1}\right)$ & $2.09 \mathrm{D}$ & $2.09 \mathrm{D}$ & $2.09 \mathrm{D}$ & $2.09 \mathrm{D}$ & $2.09 \mathrm{D}$ & $2.09 \mathrm{D}$ & $2.09 \mathrm{D}$ \\
\hline Dipole moment of acetone $\left(\mu_{2}\right)$ & $2.90 \mathrm{D}$ & $2.90 \mathrm{D}$ & $2.90 \mathrm{D}$ & $2.90 \mathrm{D}$ & $2.90 \mathrm{D}$ & $2.90 \mathrm{D}$ & $2.90 \mathrm{D}$ \\
\hline Polarizability for water $\left(\alpha_{1}\right)$ in $A^{03}$ & 1.48 & 1.48 & 1.48 & 1.49 & 1.49 & 1.49 & 1.54 \\
\hline Polarizability for acetone $\left(\alpha_{2}\right)$ in $A^{03}$ & 7.51 & 7.65 & 7.88 & 8.81 & 10.10 & 10.48 & 11.72 \\
\hline Binding energy of water-water $\left(E_{12}\right)(\mathrm{KJ} / \mathrm{mol})$ & -13.45 & -13.50 & -13.50 & -13.50 & -13.98 & -13.98 & -13.98 \\
\hline Enthalpy of water-water $\left(\alpha_{11}\right)(\mathrm{KJ} / \mathrm{mol})$ & 28 & 28 & 28 & 28 & 28 & 28 & 28 \\
\hline Enthalpy of water -acetone $\left(\alpha_{11}\right)(\mathrm{KJ} / \mathrm{mol})$ & 41 & 41 & 41 & 41 & 41 & 41 & 41 \\
\hline Number fo hydrogen bonds (m) & 3 & 3 & 3 & 3 & 3 & 3 & 3 \\
\hline
\end{tabular}

formed in the mixture. We have used the same model to explain the static dielectric permittivity of water-acetone and water-dioxane solutions. The static dielectric constant in terms of the Kirkwood correlation factor $g_{i}$ for a mixture can be determined using the Kirkwood-Fröhlich equation [22].

$$
\left[\frac{\left(\varepsilon_{0}-\varepsilon_{\infty i}\right)\left(2 \varepsilon_{0 i}-\varepsilon_{\infty i}\right)}{9 \varepsilon_{0 i}}\right]=\frac{4 \pi}{9 K T} \sum_{i=1}^{2} g_{i} \rho_{i} \mu_{i}^{2}
$$

where $i=1,2$ represent water and solute, respectively; $\mu$ is the corresponding dipole moment in the gas phase, $\rho_{i}$ is the density, $k$ is the Boltzmann constant, $T$ is the temperature, and $g_{i}$ is the Kirkwood correlation factor for the $i$-th liquid system. The Kirkwood correlation factor is a parameter affording information regarding the orientation of electric dipoles in the aqueous system. The correlation factors $g_{1}$ and $g_{2}$ were computed using the Luzar model by considering only the hydrogen bond contribution to the dipole-dipole correlation and are described by the relations [22]

$g_{1}=1+Z_{11} \cos \varphi_{11}+Z_{12} \varphi_{12}\left(\mu_{2} / \mu_{1}\right)$,

$g_{2}=1+Z_{21} \varphi_{21}\left(\mu_{1} / \mu_{2}\right)$,

where $Z_{11}=2\left\langle n_{\mathrm{HB}}^{11}\right\rangle ; Z_{12}=2\left\langle n_{\mathrm{HB}}^{12}\right\rangle$ and $Z_{21}=$ $2\left\langle n_{\mathrm{HB}}^{21}\right\rangle \frac{X}{1-X}$ are the average number of particles forming the hydrogen bond with water-water and water-solute pairs, respectively. $X$ is the mole fraction of water. $\varphi_{11}$ and $\varphi_{12}$ are the angles between the neighboring dipoles of water and solute molecules. The values of $g_{1}$ and $g_{2}$ for water-solute mixtures are computed by using the molecular parameters given in Table. The values of $g_{1}$ and $g_{2}$ depend on the concentration of a solute in aqueous solutions.

The average numbers of hydrogen bonds $\left\langle n_{\mathrm{HB}}^{11}\right\rangle$, $\left\langle n_{\mathrm{HB}}^{12}\right\rangle$, and $\left\langle n_{\mathrm{HB}}^{21}\right\rangle$ per water molecule for $1 i$ pairs

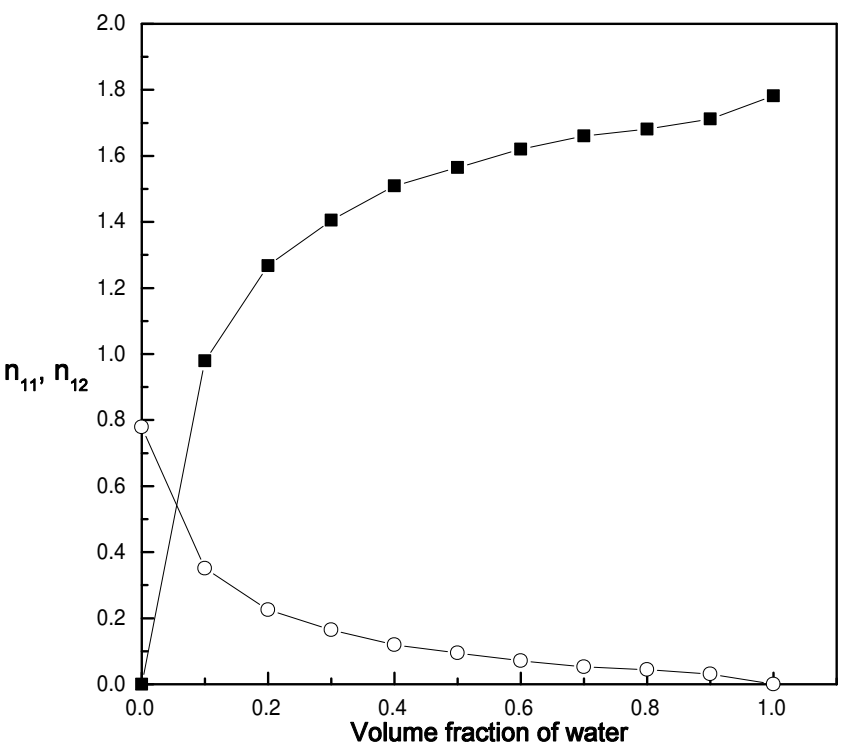

Fig. 3. Volume fraction of $n_{11}$ and $n_{12}:-\mathbf{-}, n_{11} ;--_{--}, n_{12}$

$(i=1,2)$ have been determined according to the relation $[18,19]$.

$\left\langle n_{\mathrm{HB}}^{1 i}\right\rangle=n_{1 i} \omega_{1 i} / n_{1}$,

where

$\omega^{1 i}=\frac{1}{1+\alpha^{1 i} e^{-\beta^{1 i} E^{1 i}}}$

is the probability of bond formation between water and a solute, and $n_{1}$ is the number density of water molecules. The value of $\beta=\frac{1}{k T}$, and $\alpha^{1 i}$ is the ratio of the two subvolumes of the phase space related to the non-hydrogen bonded and hydrogen bonded pairs. These hydrogenbonded pairs have only two energy levels, $E^{11}$ and $E^{12}$, for water-water and water-solute pair formed bonds, respectively.

The values of $\left\langle n_{\mathrm{HB}}^{11}\right\rangle$ and $\left\langle n_{\mathrm{HB}}^{12}\right\rangle$ depend on the number of densities of hydrogen bonding pairs between water and acetone, $n_{12}$, and those between water molecules 


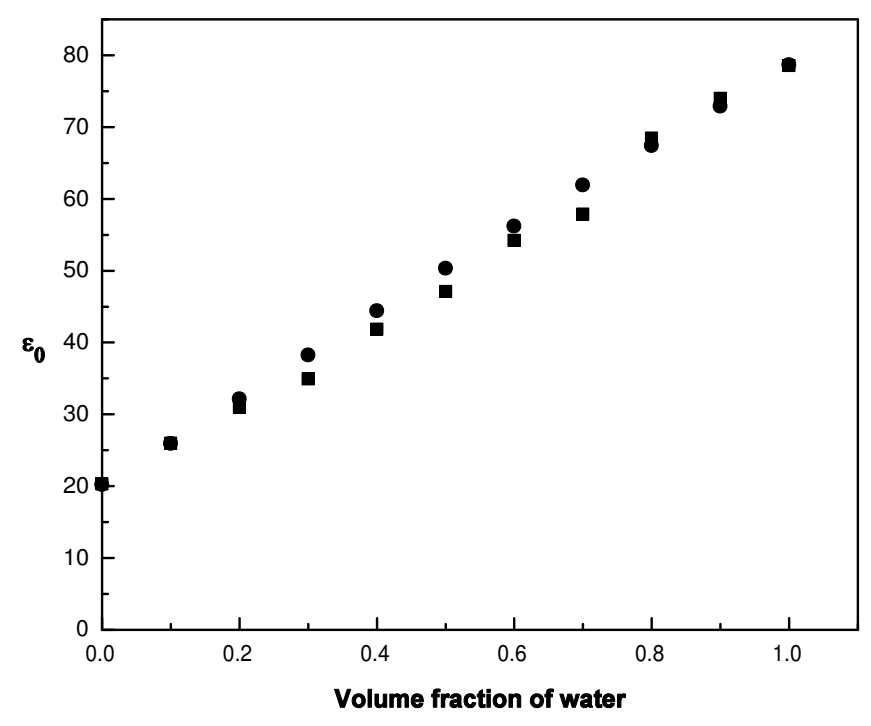

Fig. 4. Static dielectric constant vs the volume fraction of water: $\square$, exp.; •, theor.

are $n_{11}=2 n_{11}-n_{12}$. Figure 3 shows a plot of the average number of hydrogen bonds between water-water molecules (11 pairs) and water-solute (12 pairs) against the volume fraction of water. It can be seen from the values that $n_{11}$ and $n_{12}$ depend on the concentration of water in a solute-water mixture. The different parameters are required to explain the hydrogen bonding model, such as the dipole moments $(\mu)$ of water (1) and solute (2) molecules, polarizabilities of molecules 1 and 2 , energies and enthalpies of $(1,1)$ and $(1,2)$ pairs, and a possible number of bonding with molecule 2 . In our analysis, the best possible values of the molecular parameters, for which the theoretical static dielectric constants are in agreement with experimental values, are given in Table. The theoretical values of static dielectric constants at $25{ }^{\circ} \mathrm{C}$ determined from the hydrogen bonding model along with the experimental values obtained by the TDR technique are shown in Figure 4.

\section{Conclusions}

The complex dielectric permittivities for aqueous solutions are determined with the use of the TDR method. The dielectric constant for the mixtures can be explained using the hydrogen bonded model by assuming the formation of hydrogen bonds between water-water and water-solute pairs. The orientational correlations between neighboring molecules due to the hydrogen bonding interaction are determined in terms of the Kirkwood factors. The numbers of hydrogen bonds of water-water and water-solute molecules are also computed. The temperature-dependent dielectric relaxation parameters and the Kirkwood correlation factors have been reported for aqueous solutions. The hydrogen bonded model as suggested by Luzar can explain the static dielectric constant of mixtures.

The financial support from the Department of Science and Technology (DST), New Delhi, is thankfully acknowledged (Project No. SR/S2/LOP-25/2007). Special thanks are to Prof. S.C. Mehrotra, Department of Computer Science and Information Technology, Marathwada University, Aurangabad for the useful discussion and many helpful suggestions.

1. R.H. Cole, J.G. Berberian, S. Mashimo, G. Chryssikos, A. Burns, and E. Tombari, J. Appl. Phys. 66, 793 (1989).

2. S.O. Nelson and L. Onsager, A SAE 18, 714(1975).

3. S. Sudo, N. Shinyashiki, Y. Kitsuki, and S. Yagihara, J. Phys. Chem. A 106, 458 (2002).

4. Y. Li-jun, Y. Xiao-Qing, H. Ka-Ma, J. Guo-Zhu, and S Hui, Int. J. Mol. Sci. 10, 1261 (2009).

5. U. Kaatze, R. Pottel, and M. Schafer, J. Phys. Chem. 93, 5623 (1989).

6. S.M. Puranik, A.C. Kumbharkhane, and S.C. Mehrotra, J. Microwave Power and Electromag. Wave 26, 196 (1991).

7. A.C. Kumbharkhane, S.M. Puranik, and S.C. Mehrotra, J. Chem. Soc. Faraday Trans. 87, 1569 (1991).

8. J. Hubbard and L. Onsager, J. Chem. Phys. 67, 4850 (1977).

9. A.C. Kumbharkhane, M.P. Lokhande, S.N. Helambe, S. Doraiswamy, and S.C. Mehrotra, Pramana-J. Phys. 46, 91 (1996).

10. M.I. Shakhparonov, and Ya.Yu. Akhadov, Zh. Strukt. Khim. 6, 21 (1965).

11. D.S. Venables and A.S. Charles, J. Chem. Phys. 113, 11222 (2000).

12. R. Ludwig and M.D. Zeidler, J. Mol. Liquids 57, 181 (1992).

13. U. Kaatze and V. Lonnecke-Gabel, J. Mol. Liquids 48, 45 (1991).

14. A.C. Kumbharkhane, S.N. Helambe, S. Doraiswamy, and S.C. Mehrotra, J. Chem. Phys. 99, 10 (1994).

15. S.M. Puranik, A.C. Kumbharkhane, and S.C. Mehrotra, J. Chem. Soc. Faraday Trans. 88, 433 (1992).

16. Yan Zan Wei, A.C. Kumbharkhane, M. Sadeghi, J.T. Sage, W.D. Tian, P.M. Champion, S. Sridhar, and M.J. McDonald, J. Phys. Chem. 98, 26 (1994).

17. A.C. Kumbharkhane, M.N. Shinde, S.C. Mehrotra, N. Oshiki, N. Shinyashiki, S. Yagihara, and S. Sudo, J. Phys. Chem. A 113, 10196 (2009). 
18. S. Harviliak and S.A. Negami, J. Polym. Sci. Part. C 14, 99 (1996).

19. J. Barthel, K. Bachhuber, R. Buchner, and H. Hetzenauer, Chem. Phys. Lett. 165, 369 (1990).

20. J. Kaatze, R. Behrends, and R. Pottel, J. Non. Cryst. Solids 305, 19 (2002).

21. T. Fukasawa, T. Sato, J. Watanabe, Y. Hama, W. Kunz, and R. Buchner, Phys. Rev. Lett. 95, 197802 (2005).

22. A. Luzar, J. Mol. Liquids 46, 221 (1990).

Received 21.01.11
СТРУКТУРНА ПОВЕДІНКА ВОДНИХ РОЗЧИНІВ МЕТОДОМ ЧАСОВОЇ РЕФЛЕКТОМЕТРІЇ

А.К. Кумбархан

Р е $з$ ю м е

Розвинуто метод часової рефлектометрії, що дає інформацію про діелектричну проникність у діапазоні від 10 МГц до 30 ГГц. Діелектричну проникність водних розчинів розглянуто в моделі, де водневі зв'язки наявні в парах молекул вода-вода та вода-розчинна речовина. Визначено кореляцію орієнтацій сусідніх молекул, що взаємодіють за допомогою водневих зв'язків з використанням кореляційного фактора Кірквуда. Розраховано частину водневих зв'язків для деяких водневих розчинів. 